\title{
Aesthetic Interpretation of Lin Yutang's Translation from the Perspective of Western and Eastern Cultural Background
}

\author{
Zhang Huarong \\ Master Graduate, The Engineering \&Technical College of Chengdu University of Technology, The foreign Language Department \\ of The Engineering \&Technical College of Chengdu University of Technology, 614000.
}

\begin{abstract}
Most of Lin Yutang's writings are about western and eastern culture. Aimed at introducing Chinese culture to western countries and introducing western cultures to China, he had performed his duties as a cultural ambassador through a series of excellent works and translations. Apart from numerous translation works, he had also written a long essay On Translation which systematically explained his understanding and attitude of translation from multi angles. At that time, Lin Yutang's translation theories are original creations and forward thinking. Therefore, this translator who integrates both translation theories and practices has provided many meaningful topics for studies in translation area.
\end{abstract}

Index Terms - Lin Yutang, Translation, Aesthetic

\section{Choices of Form and Meaning in the Translation of Verses}

Compared with other literal forms, verses are special in sentence structures, voices and rhythms, so translation of such texts are different from other literal forms. Mr. Xu Yuchong had come up with his three standards for translation of poems, namely beauty of meaning, beauty of sound and beauty of form, which means that forms, as important as meaning in translations of poems, are used to evaluate the success of translation. Therefore, to evaluate Yin Yutang's translation of verses calls for analysis from two aesthetic categories: forms and meanings. What's for sure is that Yin Yutang's translation of Chinese verses is not only influenced by his translation theories but also by other objective factors. Therefore, to discuss his translation of verses from cultural aspects is an effective means to understand specific appearances in his translation.

\section{A. Give Up Meanings for the Sake of Forms}

Mr. Lin thought that poem cannot be translated from the aspect of aesthetics, that is to say, it is impossible to meet all the requirement and standard of both meaning and form. Therefore, in translation activities only one aspect can be focused on, which is mainly determined by factors such as target reader and the translation ideology and purpose of translator. In his article On Poetry Translation, Mr. Lin suggests that artistic conception of poem should be given top propriety when translating. Artistic conception means the image of the work with the scenery depicted and the emotions expressed in perfect harmony. So one of the pursuit of Lin's translation of poem is to achieve the originally imagination.

However, when meanings and forms cannot be achieved at the same time, translator can only put more emphasis on one standard. Based on Lin's translation targets, we can see his cultural positions which influence his aesthetic standards through his emphasis on form and meanings. One outstanding feature of Lin's translation of Chinese verses is that he gives up the correctness of meanings for the sake of forms. When the original contents are weakened, cognitive needs and expectations of target languages readers are strengthened, which shows that translators' cultural positions tend to emphasis on target languages.

\section{B. Give up Forms for the Sake of Meanings}

Opposite to giving up meanings for the sake of forms, to give up forms for the sake of meanings seems to be a contradictory attitude in Lin's translation of verses. Just as its name implies, to give up forms for the sake of meanings is mainly focused on faith expression of original texts, therefore its requirement for forms, including metres, sentence length and rhymes.

See from aesthetic view, forms in translation of poems are important standards to evaluate whether the translation is successful or not. Lin also believed that beauty is an important standard in translation of poems, so we need analyze his intentions as he gives up forms for the sake of meanings. Compared with forms, faith expression of meanings better reflects that translators attach importance to original texts and writers. Therefore, Lin is out of respect when he regards meanings as the most important while translating. Chinese poems are important types of Chinese classic literature, and its concise words are always with profound meanings; compared with Chinese poems, English poems create artistic conception through rhythms, metres and sounds, and its meanings are expressed directly. Therefore, faith expression of original meanings embodies Lin's loyalty to Chinese culture and deep eastern cultural complex.

\section{Consider both Meanings and Forms}

As there're many differences in expression of meanings and aesthetic judgment of forms, it's very difficult to be faith to meanings and forms of original texts and accord with aesthetic expectations of translation. Therefore, seen from translation effects, Mr. Xu Yuanchong's standards of "beauty of meaning, beauty of sound and beauty of form" are ideal requirements for translations of verses. 
Seen from translators' duty, a translator is responsible both to original texts and writers and readers if he considers both faith expression of meanings and aesthetic features of forms. In this way, in the cultural dialogues of two languages, cultures of source cultures and target cultures are also given fair consideration. In Lin's translation of Chinese poems, there're lots of such excellent examples, which not only embodies his profound foundation of Chinese and English, but also reflects his dual cultural positions, namely he tries to keep features of eastern culture and cater to understanding and expectations of western readers.

\section{Aesthetic Representation of Fuzzy Language}

The definition of fuzziness in literature is that "Things are still not definite even though speakers have considered carefully the states when things may have several states, and one cannot decide whether the state belongs or not to the proposition." Fuzziness is a general character of literatures, and good literature cannot lack beauty of fuzziness and connotation. Precision of languages are relative, but uncertainty can inspire readers to have more explanation of the work. The fuzzier a work is the more freedom readers can have during re-creation. On the contrary, if a literary work is clear and precise, the dim and mysterious artistic conceptions will disappear, and its literary charm will also be weakened.

First, when it comes to contents that cannot be expressed directly, fuzzy language is an effective indirect means. Second, fuzzy language is rich in historical and cultural contents, so readers can learn its rich meanings concealed in the languages and appreciate its aesthetic effects.

\section{A. Fuzzy Skills}

Fuzzy languages bring readers rich association space, and translators can also enable target readers enjoy such association if they can reappear the fuzzy effects of languages. On the contrary, the beauty of translated texts will be reduced if a translator changes fuzzy words into clear words for the sake of clear understanding. Aesthetic expectations of English and Chinese cultures are different, but if translated texts can bring the same broad imagination effect as that of original texts, its aesthetic effects are achieved. By fuzzy translation of fuzzy languages in the original texts, Lin Yutang gives rich imagination to translation, which is an effective means to consider both aesthetic cultures of original texts and aesthetic expectations of target readers.

\section{B. Combining Fuzzy Technique with Complementary Methods}

The fuzzy language in target language is to provide target readers with the corresponding imaginary space, so as to meet their aesthetic demand of translation. However, it is impossible for translator to offer equal imagination space for target readers with source-text readers. First of all, the target readers have obvious individual characteristic, in other words, a different understanding to the same work.
The translators, as individual reader themselves, are hard to avoid their unique comprehension and expression in target language even with the mission of conveying original message objectively. Secondly, Chinese and English belong to two completely different language culture systems. Therefore, it is unavoidable for readers to have different understanding and psychological feelings for the same language phenomenon. Under such premise, it is not enough to translate source language with fuzzy language to meet the aesthetic needs of target readers. Complementary methods are necessary to fully convey the information of source text.

To sum up, fuzzy language in translation is an effective way to meet the aesthetic requirement of target readers. However, it must not convey contradict meaning. Certain complementary methods are necessary to coordinate both sides. It also reflects Lin Yutang's efforts in keeping the culture aesthetic meaning of original text and catering to the understanding and aesthetic expectation of western readers.

\section{Direct Expression of Fuzzy Language}

As many of Lin's original texts are classical style of writing, there're inevitably many phases of literary quotation or idioms. Due to the differences of cultural cognitive environment between western and Chinese readers, such phrases are difficult to be appreciated by English readers. If such phrases are translated directly into English, English readers will have difficulties in understanding, and more in aesthetic experiences of Chinese readers. As texts of target language lack direct experiences and its readers lack direct feelings of source language texts, translator should try to overcome the sense of distance and establish link between history and reality so as to dissolve distance of time and enable appreciation of beauty as if one is in the same position. On this occasion, translators are necessary to use clear and direct expressions to achieve translation objectives. In practice, Lin Yutang adopted the methods of using direct and clear language and effectively eliminated target readers' estrangement of understanding.

The use of fuzzy language in the text is to enable the target readers to appreciate it. However, when the fuzzy language is beyond the understanding ability of target reader, the translator has to literally translate the original language. In the translation process, Mr. Lin obviously tends to extend the actual meaning of original language. Relatively speaking, the aesthetic meaning of the original language is ignored in a certain sense. Mr. Lin's intention to cater to the target readers' expectation is obvious.

All in all, the uncertain meanings and images of fuzzy language have offered readers rich imagination. As interpreters and carriers of fuzzy language, translators should not only be responsible for spreading the information of original texts, but also re-introduce aesthetic effects of original texts and bring the images original readers appreciate to target readers. But this is only an ideal state of translation. first, imagination of original texts are difficult to define as different translator have their 
individual interpretation; second, fuzzy language of original texts sometimes go beyond the target readers' scope of understanding and appreciation, in which case reappearance of fuzzy language can only make it more difficult for target readers to understand the texts. Therefore, translators need to be flexible so as to strike a balance between information and esthete. We can see Lin's eastern cultural complex and the contradiction and unity of inevitable orientalism from those flexible translation methods and the relationship between translators and readers of both target and source language.

\section{Conclusion}

Lin Yutang's eastern cultural complex and tendency of orientalism intermingle in his translation and writings, which have become contradictory and unified features of Lin's cultural views toward the two cultures. Special cultural environment has facilitated Lin's contradictory and unified cultural views, and cultural views will inevitably have inter-textual relationships with translation. The dual cultural background of western and eastern cultures has bestowed special cultural identity of Lin Yutang. It's just this complex cultural identity that embodies a contradictory and unified cultural tendency in his literary creations and transition activities.

The oriental culture cultivates Lin Yutang's strong interest and emotion of oriental philosophy, religion, literature, history and aesthetics. This kind of oriental culture emotion is obviously shown in his works. At the same time, the family background of Christian priest, education in missionary school and overseas life experience of 30 years enable Mr.Lin have deep understanding of western culture. In the meantime of enjoying the convenience of western industrial development, Lin also realized the lack of spiritual life in materialized western countries.

Those two different cultural factors influenced Lin's cultural views at the same time. On one hand, his love for Chinese cultures have made him vigorously introduce eastern philosophy dominated by Confucian political ethics and Taoist ideas and essences of eastern literatures to western countries, and safeguard and advertise those contents from China. On the other hand, in western countries where cultures are highly advanced, Lin Yutang is constrained by many factors such as market demands, readers' expectation of eastern cultures, aesthetic expectations and cultural expectations, so cultures he spreads out is not random or mechanical. To cater to western expectations and tastes of eastern cultures, he had made adjustments and changes to western cultures, which have become his western tendency in his cultural position. Lin Yutang's eastern cultural complex and tendency of orientalism intermingle in his translation and writings, which have become contradictory and unified features of Lin's cultural views toward the two cultures. Special cultural environment has facilitated Lin's contradictory and unified cultural views, and cultural views will inevitably have inter-textual relationships with translation.

In the culture perspective, through intertextuality analysis, the characteristics of Lin's translation can be concluded and reasonably explained. First of all, on the choice of the source language text, Lin yutang tended to choose literary works which embodied Chinese Taoist philosophy thoughts, especially texts that advocated themes of spirit, leisure and contentment. Secondly, Lin's translation strategies can be divided into different types from cultural perspectives; one can find the shadow of cultural views behind every strategy if he/she analyzed through the theory of intertextuality. To sum up, characteristics of any translator is not accidental. The study of Lin's translation cannot be separated from the study of his special cultural identity. Through intertextuality analysis, the cultural viewpoint of Mr. Lin can provide a reasonable explanation for complex translation phenomenon, and also a way for rational understanding his translation.

\section{References}

[1] Bassnett, Susan. Translation Studies. London and New York: Routledge, 1991.

[2] Even-Zohar, Itamar. The Position of Translated Literature within the Literary Polysystem. Poetics Today, 1990.

[3] Lin Yutung. A Nun of Taishan and Other Translation. Shanghai: The Commercial Press Limited, Shanghai, China, 1936.

[4] Hatim, Basil. Communication across Cultures: Translation theory and Contrastive Text Linguistics. Shanghai: Shanghai Foreign Language Education Press, 2001.

[5] Lin Yutung. Between Tears and Laughter. New York: John Day Company, 1943.

[6] Hermans, Theo. Introduction: Translation Studies and a New Paradigm. Hermans, Theo. ed. The Manipulation of Literary Translation. London \& Sydney: Croom Helm. 1985. 